\title{
Overscheduled and glued to screens - children are sleeping less than ever before
}

\author{
— Cite as: CMAJ 2018 December 3;190:E1428-9. doi: 10.1503/cmaj.109-5676
}

Posted on cmajnews.com on Nov. 14, 2018.

W hen Angela Grant Buechner's daughter was 12 , she started babysitting, and she needed a cell phone so her mother could check in with her. Grant Buechner, a nurse, is well aware of the importance of sleep for children's learning and development. She enforced a technology shutdown an hour before bedtime. "I've always been one of those sticklers," she says. "My kids always go to bed earlier than their friends and I don't care."

But when summer rolled around, Grant Buechner was lax about enforcing screen time limits, and her daughter started complaining that she was lying in bed and couldn't sleep. The solution: a nightly alarm reminder to end phone time. The effects were immediate; Grant Buechner's daughter no longer had issues falling asleep.

Some studies have shown that kids are getting less sleep than they did a decade ago, and the trend is noticeable at younger ages. That's concerning, given the brain development occurring at these ages, according to experts.

"The same trend [of inadequate sleep] that we first saw in adolescence is now appearing very significantly in children," says Reut Gruber, a pediatric sleep expert and associate professor in McGill University's department of psychiatry. Her study examining the sleep habits of children in Quebec, published in Sleep Medicine in July, found that $96 \%$ of kids aged six and seven got the recommended 9-11 hours of sleep per night, but only about half of kids aged 10 and 11 met the requirements.

In addition, the amount of variability in sleep from one night to the next increased dramatically. "We don't always think about variability, but sleep and wakefulness is a circadian rhythm and in order for this to function well, there should be some consistency," she says.

What's to blame? Screen time is a major factor, as is kids' increasingly scheduled lives.

Gruber doesn't blame parents. "The challenges for parents today have gotten way more complicated than even five years ago," she says. Kids don't just have TVs and laptops, but also tablets, phones and learning games with screens. Plus, parents may pick up their kids late from after-school care or extracurricular activities. "It's all a vicious cycle; they want to be able to spend time with their kids," she says. "And they're told their kids should do more physical activity... so bedtime can be pushed very late."

Sleep deprivation in kids has worsened in recent years. One study looking at data from 20 countries found that the sleep duration of children aged 5-18 declined by about an hour from 1995 to 2008. It's likely the downward trend will continue, says Jean-Philippe Chaput,

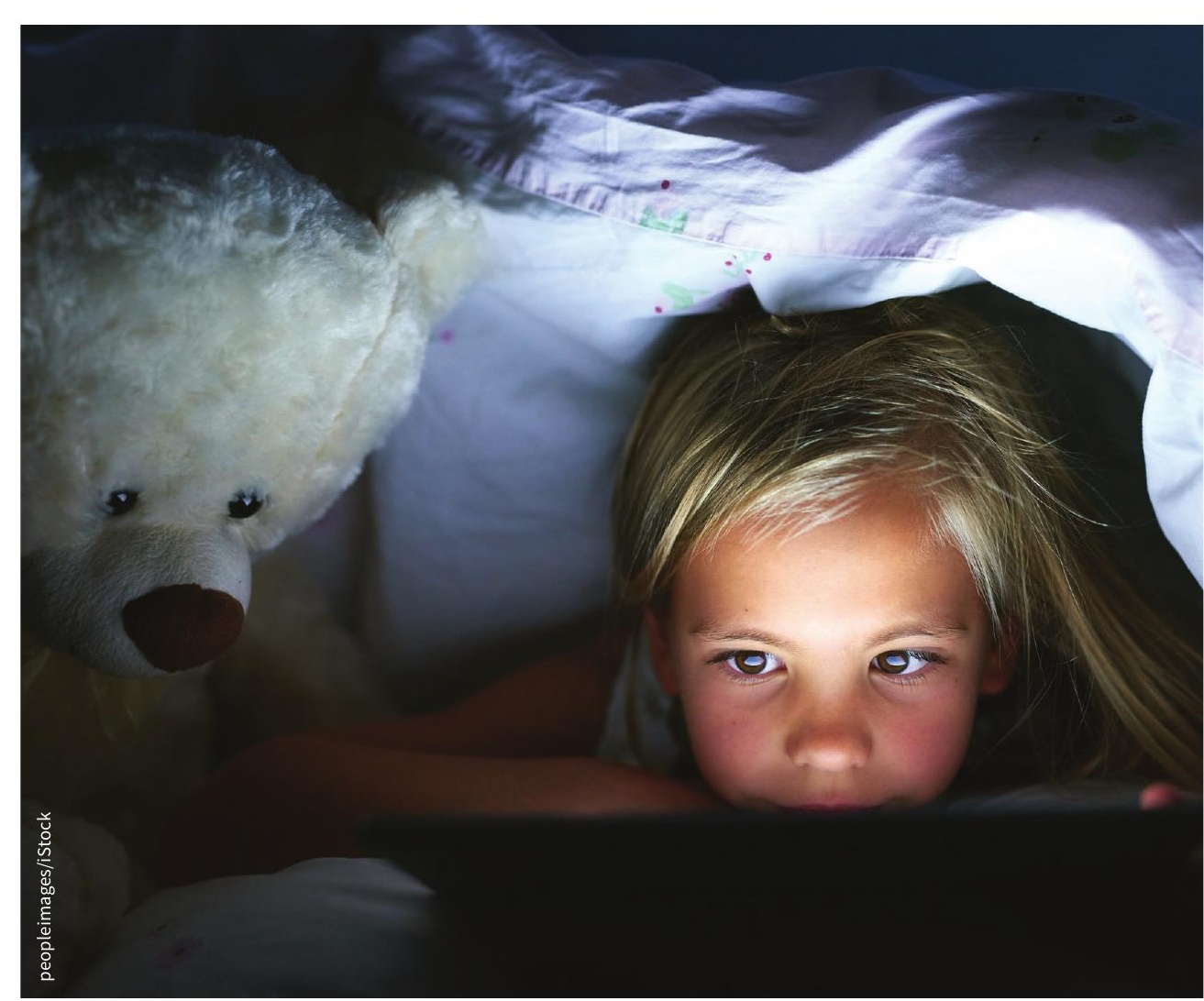

Managing screen time is one component of ensuring children get enough sleep. 
associate professor of pediatrics at the University of Ottawa. "We have a lot of sleep stealers, and screen time is a big one. We know that the blue light sends a wrong signal to our brain," he says.

The lack of sleep has serious repercussions. A study published this September in The Lancet Child \& Adolescent Health looked at physical activity, sleep and screen-time data for 4520 children across the United States. Nearly a third of the children didn't meet any of the recommendations for exercise, sleep duration or screen-time limits. Those that did meet the recommendations on these indicators performed better on a cognition test, after controlling for factors such as household income and parental education.

The effect on cognitive ability is especially concerning to researchers because it is an umbrella for several markers. "Behaviour can be impacted, mood, a child's well-being, their ability to focus in school and learn new concepts ... all these things stem from cognition," says Jeremy Walsh, the study's lead author.

Some software developers are aware of the growing problem of sleep deprivation in children and are devising their own solutions. The latest iPhone update, for example, provides automatic screen-time notifications. Grant Buechner's daughter discovered and now uses an app with virtual trees that grow faster the less often she uses her phone.

Of course, there are no easy solutions, given the pressures of work, school and extracurricular activities. Instead, society needs to start taking kids' sleep more seriously, suggest sleep researchers. "As adults, we say we can sleep for the week on the weekend," says Walsh. "But sleep is actually a very active time for the brain. It's building and solidifying connections from previous learning in the day."

Wendy Glauser, Toronto, Ont. 